\title{
Analysis on the effect of ECDM process parameters during micro-machining of glass using genetic algorithm
}

\author{
B. Mallick ${ }^{*}$, B.R. Sarkar ${ }^{2}$, B. Doloi ${ }^{2}$, B. Bhattacharyya ${ }^{2}$ \\ ${ }^{1}$ Research Scholar of Production Engineering Department, Jadavpur University, \\ Kolkata-700032, INDIA \\ Phone: 009109432663186; Fax: 009109831993552 \\ ${ }^{2}$ Faculty of Production Engineering Department Jadavpur University, Kolkata-32, INDIA \\ ${ }^{* 1}$ Email: bijan.ju@ gmail.com
}

\begin{abstract}
Electro chemical discharge hybrid machining process involves in micro-machining to cut microchannel, micro-profile as well as micro-slot, blind hole on hard materials like ceramic, quartz and glass. Experimentation has been performed using an indigenously developed micro-ECDM set up in which pressurized automated spring feeding mechanism and cam follower system is used to control the working gap. This paper emphasis to the influences of different process parameters like applied voltage $(\mathrm{V})$, electrolyte concentrations $(\mathrm{wt} \%)$, pulse frequency $(\mathrm{Hz})$ and duty ratio $(\%)$ on different machining performance characteristics such as Material Removal Rate (MRR), Overcut (OC), Surface Roughness $\left(\mathrm{R}_{\mathrm{a}}\right)$ and Heat Affected Zone (HAZ) during micro-channel cutting on glass. The empirical mathematical model has been validated by the analysis of variances. This research paper rendered the suitable optimal parametric condition during single as well as multi objective optimization using genetic algorithm (GA). Applied voltage and duty ratio has dominating role to increase MRR, OC, HAZ and surface roughness. Machining Depth increased using automated spring feeding with Cam-follower mechanism and achieved machining depth of $1.35 \mathrm{~mm}$. This research paper also presented the SEM analysis of micro-channel to find out the debris and other particles.
\end{abstract}

Keywords: Genetic algorithm; micro-ECDM; micro-slot; spring-feed; surface roughness

\section{INTRODUCTION}

Electrochemical Discharge micro-machining process plays a great roll in modern research of nontraditional machining process since 1968. The material removal took place due to the emerged effects of electrochemical (EC) reaction and electrical spark discharge (ESD) action [1-3]. The overall performance of ECDM process was increased by maintaining the electrode gap and the stability and robustness of the controller were higher when peak voltage was used in feedback signal [4]. Electrochemical discharges depended on the electrolyte concentration and the surface roughness of the work piece was affected by the electrolyte concentration as well as the applied voltage and also it was propounded that the gas film stability highly required and found clear sparking at 30volt during ECDM process [5]. Material removal rate, heat affected zone and overcut was affected by applied voltage and electrolyte concentration during micro-drilling on silicon nitride and achieved maximum machining rate at 70 volt, $18 \mathrm{wt} \%$ of electrolyte concentration and 27 $\mathrm{mm}$ inter electrode gap [6]. The surface roughness increased as the duty ratio increased and pulse frequency decreased during micro-drilling on glass. Increasing the drilling time, material removal rate was decreased and tool wear rate was increased when duty ratio increased [7]. The combination of flat sidewall-flat front tool and pulse voltage conspicuously increased the machining accuracy 
[8]. The precision of micro holes improved using Electro Phoretic Deposition (EPD) grinding and improved the taper angel and surface roughness of micro holes during drilling by ECDM process [9]. Tool electrode should be small and auxiliary electrode may be small or large in ECSM process [10]. The quality of the micro-holes on advanced ceramics during micro-drilling mainly depended on the applied voltage and electrolyte concentration [11]. The power circuit configuration has a great role for micro-drilling on glass and ceramics by ECDM [12]. The geometric configuration of electrochemical discharge micro-drilling was improved using an ultrasonic-vibrated system [13]. The machining efficiency and accuracy of ECDM was enhanced using the magnetic field [14]. A model was established to reveal the electric field, acting on a hydrogen bubble in ECDM process and XRD pattern was obtained for ECDM and shown that tungsten had more machining speed but tungsten carbide provided best machining performances and reached up to $150 \mu \mathrm{m}$ machining depth [15]. Tungsten carbide showed the best machining stability and least tool wear followed by tungsten and stainless steel and the break down voltage was found between 26-30V during ECDM process [16]. Electrochemical Discharge Machining was an alternative spark-based micro-machining method for producing micro-holes and micro-channels in non-conductive hard and brittle materials [17]. The gold electroplating coupled effects in ECDM was utilized and used capacitive accelerometer to improve the performances of electrochemical discharge machining process [18]. Electrochemical discharge dressing (ECDD) was applied and showed that the normal grinding force and the surface roughness of the job specimen were reduced by half after dressing [19]. Polycrystalline diamond (PCD) tools were used to reduce the machining time and improved the surface quality during hybrid ECDM process [20]. Using tapered tool electrodes improved the consistency of spark and generated an analytical model of the gas film [21]. The machined surfaces become smoother for the lower concentration of electrolyte and higher machining voltage, so the machining depth increased using magnetic field [22]. The electrical and 2D machining characteristics of ECDM process was utilized and used a dynamic cylindrical tool electrode to improve the machining performances. At $40 \% \mathrm{KOH}$ electrolyte concentration with $0.5 \mathrm{~mm}$ tool immersion depth critical current up to 0.9 ampere and critical voltage increased if tool diameter was increased [23]. The effects of applied voltage, electrolyte concentration and inter electrode gap on material removal rate, machining depth, overcut and heat affected zone was studied and showed applied voltage has important role to increase the machining depth [24]. The ultrasonic vibration and single discharge provided better results on material removal and tool wear [25]. The crystal size was increased with an increase of electrolyte temperature [26]. The effect of ultrasonic vibration on the thickness of gas film was studied and small discharges increased the material removal rate (MRR) and hole accuracy and also ultrasonic vibration increased MRR up to $82 \%$, overcut deviation improved $40 \%$ and tapering zone accuracy increased 50\% [27]. The bending force was applied on tool in the presence of magnetic field and showed that the bending force decreased when the electrolyte concentration and applied voltage is increased. Magnetic field reduced bending force at $15 \mathrm{wt} \%$ of electrolyte concentration [28]. Side insulated tool with proper diamond coating prevented the side wall discharge and achieved better surface integrity [29]. Micro-grooves of aspect ratio 1:4 were fabricated and improved the step milling depth in the ECDM process [30]. The validation of the mathematical model has been checked by analysis of variance (ANOVA) [31]. Micro-channel of $10 \mu \mathrm{m}$ diameter improved greatly the heat transfer performance of heat exchanger [32].

But till date a little attention has been drawn in the area of micro-machining on glass by the researcher. This paper analyse the influences of different parameters like applied voltage, electrolyte concentrations, pulse frequency and duty ratio on different machining performance characteristics such as material removal rate, overcut, surface roughness and heat affected zone after micro-channel cutting on electrically non-conducting materials like glass. The paper includes the empirical mathematical model of machining criteria with co-relating with process parameters and analysis of variance (ANOVA) justification has been done to validate the mathematical model. This research article also rendered the suitable parametric condition to achieve better quality of 
micro-channel as well as micro-slot and to improve the performances of micro-ECDM process based on genetic algorithm.

\section{DEVELOPED EXPERIMENTAL SET UP}

To fulfil the desired objectives of this research work and to control the process parameters such as applied voltage, duty ratio, pulse frequency, electrolyte concentration etc an experimental ECDM set-up was indigenously designed and developed. The set-up includes the following sub systems: a) main machining chamber system, b) electrolyte supply system, c) electrical power supply unit, d) automated spring feed mechanism system e) cam-follower i:e template guided system. The schematic of the micro-ECDM set-up is shown in Figure 1. All the parts and mechanism of the machining setup is presented for proper investigations.

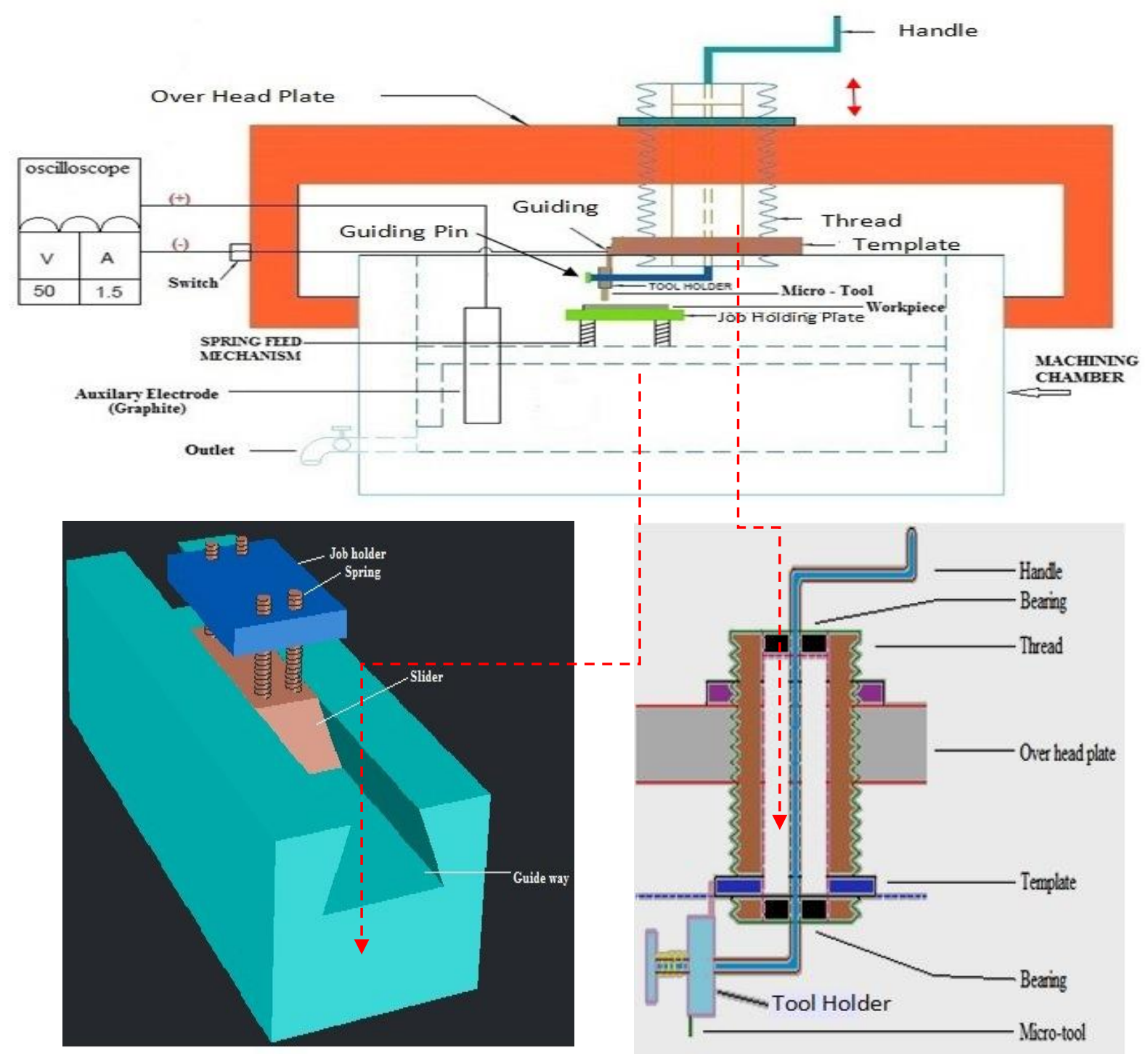

Figure1. Schematic diagram of micro-ECDM set-up. 


\section{EXPERIMENTAL PLANNING AND SCHEME}

In this experimental investigation for machining by micro-ECDM, each variable was coded and the upper level was taken as +1 and the lower level as -1 of every process parameter in order to design the experiments in an optimized way. Flat end cylindrical stainless tool of diameter $250 \mu \mathrm{m}$ were used for each experiment and the experiments were conducted in a $\mathrm{NaOH}$ solution. The process parameters i.e. voltage, electrolyte concentration, duty ratio and pulse frequency have been varied as 35-55 V; 20-30wt\%; 40-60\%, and 200-1000 Hz respectively. $\mathrm{X}_{1}=$ Voltage (1), $\mathrm{X}_{2}=$ Electrolyte concentration (2), $\mathrm{X}_{3}=$ duty ratio (3) and $\mathrm{X}_{4}=$ pulse frequency (4).

For investigations on the effects of applied voltage, electrolyte concentration, duty ratio and pulse frequency on different machining criteria such as MRR, OC, HAZ and surface roughness $\left(\mathrm{R}_{\mathrm{a}}\right)$ with the machining condition during micro-channel cutting on glass has been shown in Table 1 . Other parameters such as inter-electrode gap and length of stainless steel tool have been kept fixed as $40 \mathrm{~mm}$ and $10 \mathrm{~mm}$ respectively. Working gap which is the tool and work piece distance kept constant almost zero, approximately $1 \mathrm{~mm}$. Silica glass slide was chosen as work piece material to cut micro-channel. During experimentations one parameter has been varied while other process parameters were fixed at low levels within their respective ranges in order to expect minimum effects of these parameters. As high heat is formed during ECDM process a new identical microtool was always used for each experiment as tool wear rate (TWR) may be occurred.

MRR has been calculated by weight difference using weighing machine and the overcut and heat affected zone area of micro-channel was measured using a Leica measuring microscope. Mitutoyo 178-561-02A Surftest SJ-210 surface roughness tester with $2 \mu \mathrm{m}$ diameter stylus was used to measure the surface roughness $\left(\mathrm{R}_{\mathrm{a}}\right)$ of micro-channel.

The general second order polynomial response surface mathematical model, which analyses the parametric influences on the various response criteria, can be described as follows:

$$
Y_{u}=b_{o}+\sum_{i=1}^{n} b_{i} X_{i u}+\sum_{i=1}^{n} b_{i i} X_{i u}^{2}+\sum_{i \leq j} b_{i j} X_{i u} X_{j u}+\epsilon
$$

where, $\mathrm{Y}_{\mathrm{u}}=$ the corresponding response, e.g. MRR, OC, HAZ, $\mathrm{R}_{\mathrm{a}}$ $\mathrm{X}_{\mathrm{iu}}=$ the coded values of the ith machining parameters for $\mathrm{u}^{\text {th }}$ experiment, $\mathrm{b}_{\mathrm{o}}=$ constant, $\epsilon=$ the error, $n=$ number of machining parameters and $b_{i}, b_{i i}, b_{i j}=$ second order regression coefficients

\section{RESULTS AND DISCUSSION}

The average values of the three set of experimental results thus obtained, were used and plotted in graph to analysis the influences of the various process parameters on various machining characteristics.

\section{Parametric Influence on MRR}

The influences of applied voltage, electrolyte concentration, duty ratio and pulse frequency on average material removal rate for fixed inter-electrode gap $(40 \mathrm{~mm})$ when micro- channel is cut on glass using $\mathrm{NaOH}$ electrolyte are shown in Figures 2 (a) -(c) respectively. From the Figure 2 (a) it is observed that MRR is increased when voltage is increased because the sparking rate becomes higher as increasing voltage but at 45 volt MRR is comparatively low and become higher at 30wt $\%$ of electrolyte and lower at $20 \mathrm{wt} \%$ when the voltage is 55 volts, is found from respective mathematical model analysis. Experimental results are shown as dotted line that also revealed the mathematical models. It is propounded that at $55 \mathrm{v} / 25 \mathrm{wt} \% / 600 \mathrm{~Hz} / 50 \% / \mathrm{IEG} 40 \mathrm{~mm}$ machining rate is better to achieve maximum material removal for micro-channel cutting on glass. From the Figure 
2 (b) MRR increases with the increasing of duty ratio and electrolyte concentration based on mathematical modelling as well as experimental results. MRR increased due to increase of duty ratio because pulse on time is increased, so rate of discharge increased. From the Figure 2 (c) it is clear that MRR decreases as pulse frequency is increases, keeping other parameters constant and it is obvious that at $200 \mathrm{~Hz}, \mathrm{MRR}$ is higher and at $1000 \mathrm{~Hz}$ is lower.

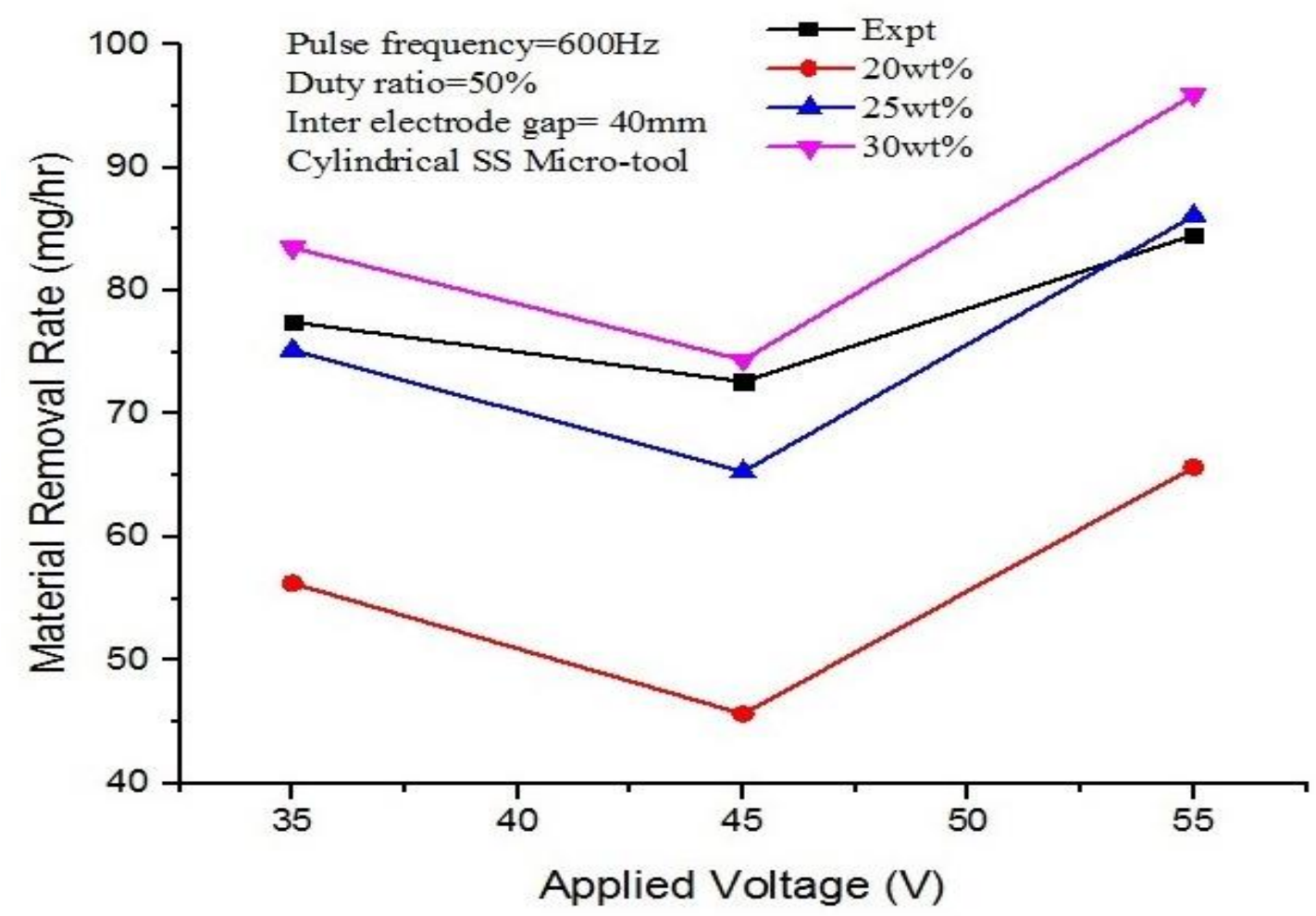

(a)

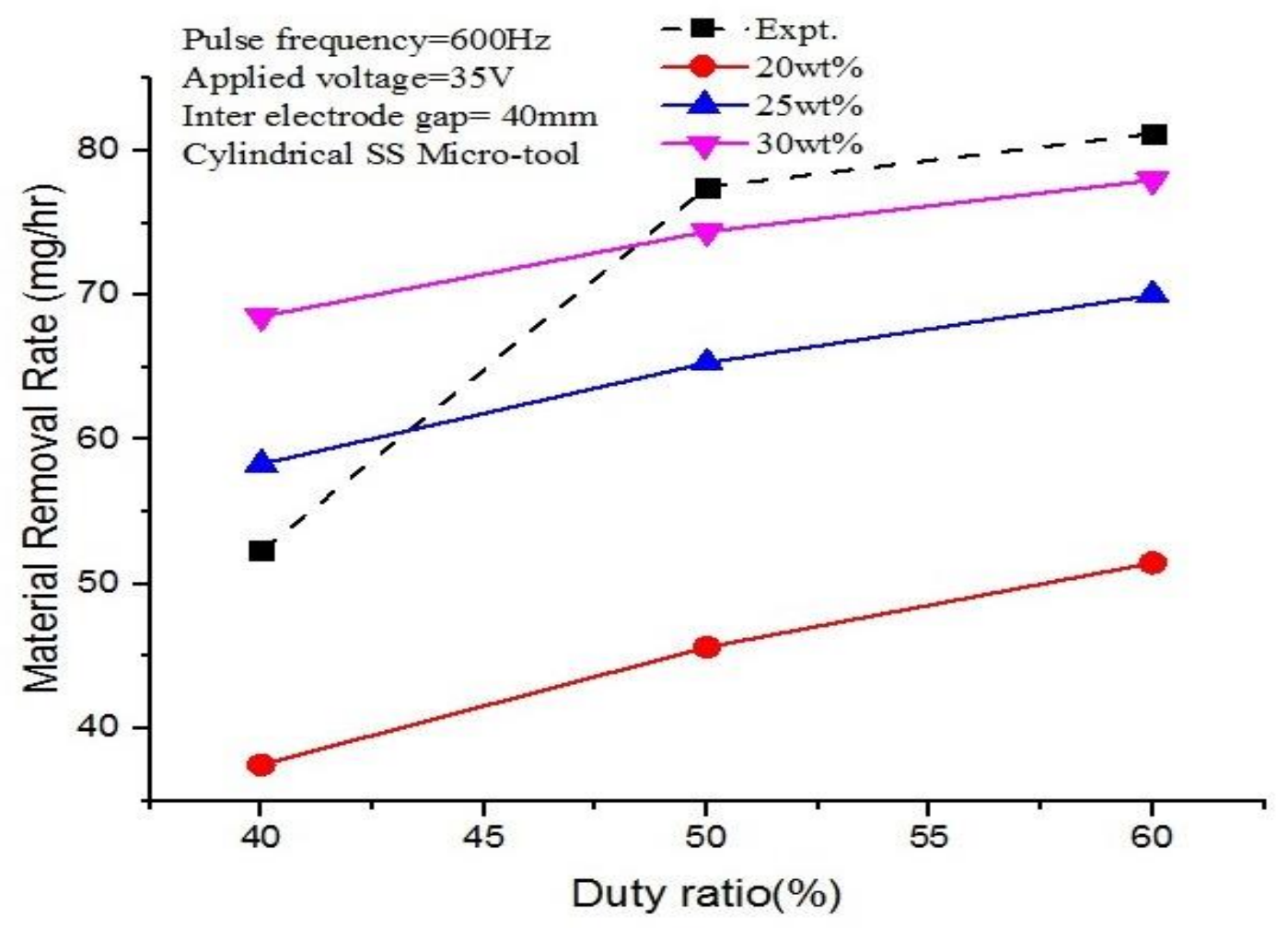

(b) 


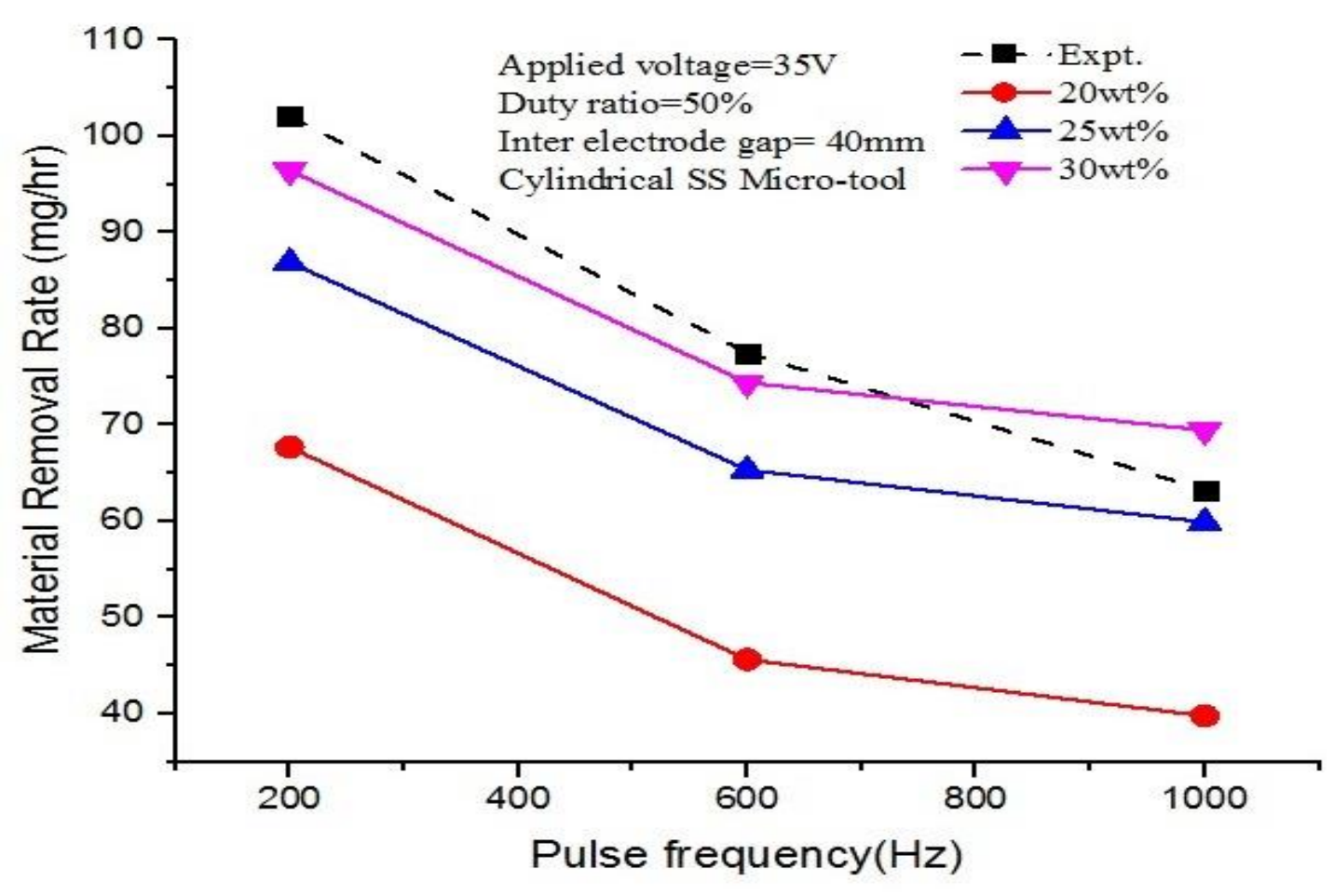

(c)

Figures 2. (a) - (c) Effect of various parameters on MRR at different electrolyte concentration (a) applied voltage, (b) duty ratio and (c) pulse frequency.

\section{Parametric Influence on OC}

Figures 3 (a) - (c) exhibit the influences of applied voltage, electrolyte concentration, duty ratio and pulse frequency respectively on average overcut using $\mathrm{NaOH}$ as electrolyte. Generally, rate of sparking increases with the increase of both applied voltage and electrolyte concentration and consequently increases not only MRR but also width of cut due to side wall sparking from the tool electrode and thereby increases overcut. From the Figures 3 (a)-(c) it is clear that overcut increases with increase of voltage, duty ratio and decreases with increase of pulse frequency. From the Figures 3 (a)-(b) it is found that overcut increases to increase applied voltage due to increasing discharge rate with violent spark and hydrogen bubble assemble in the side wall of the tool, so side sparking also happened and increasing duty ratio up to $50 \%$ OC increases and at $60 \%$ of duty ratio OC decreases, if other process parameters are kept constant. From Figure 3 (c) it is observed that OC is decreased when pulse frequency increases because intensity of discharge become low and it is found that at $200 \mathrm{~Hz}$ OC is higher. 


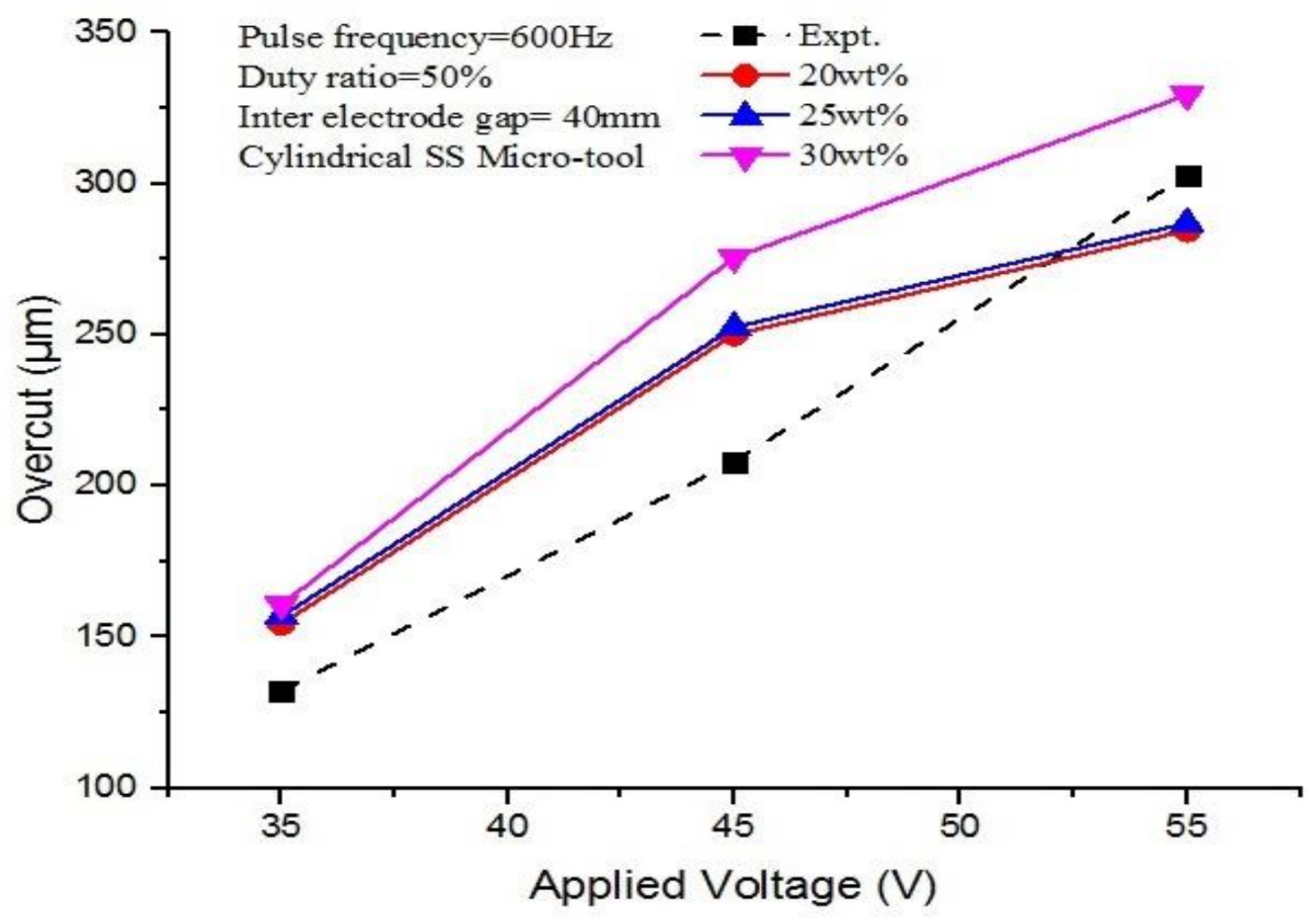

(a)

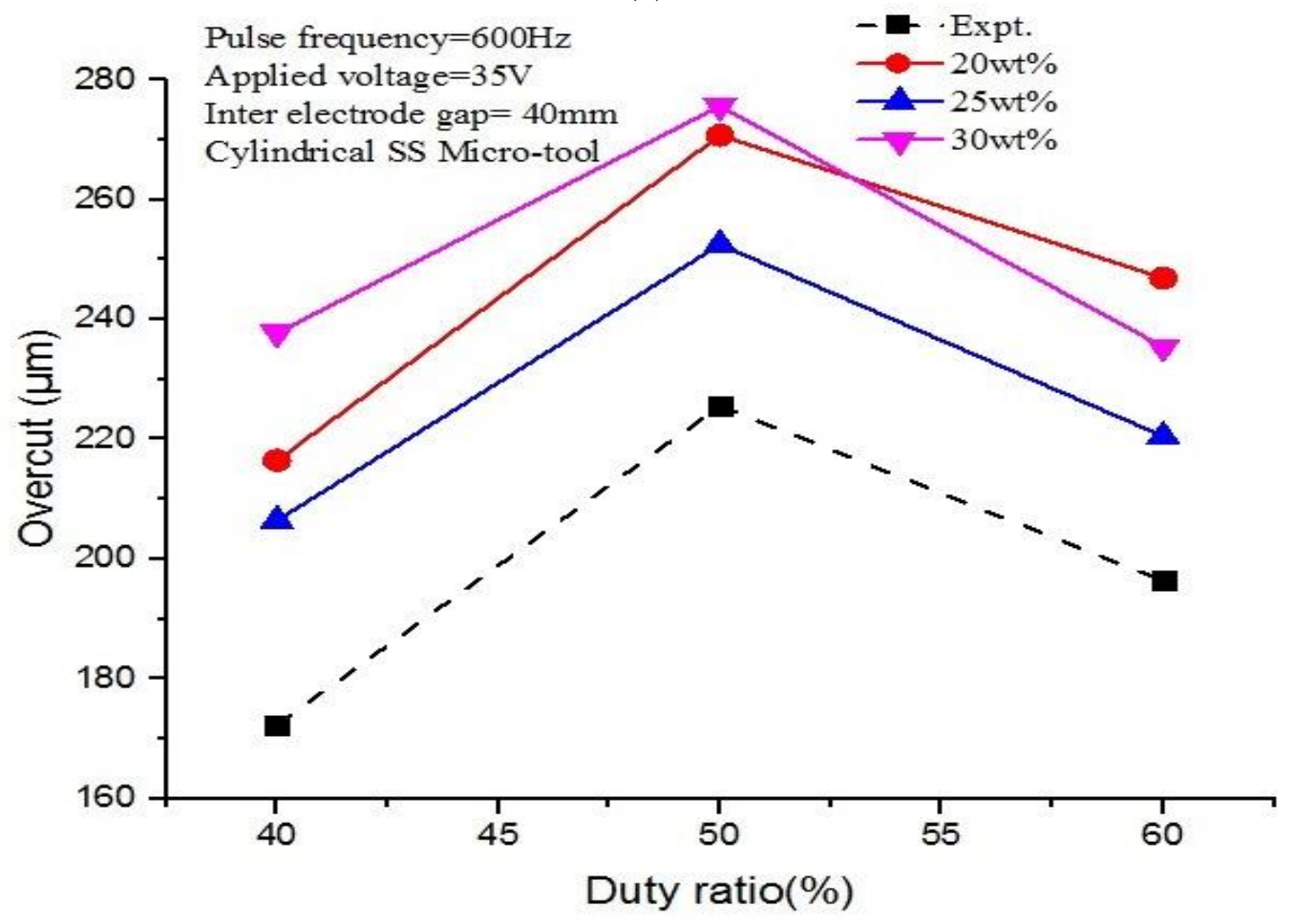

(b) 


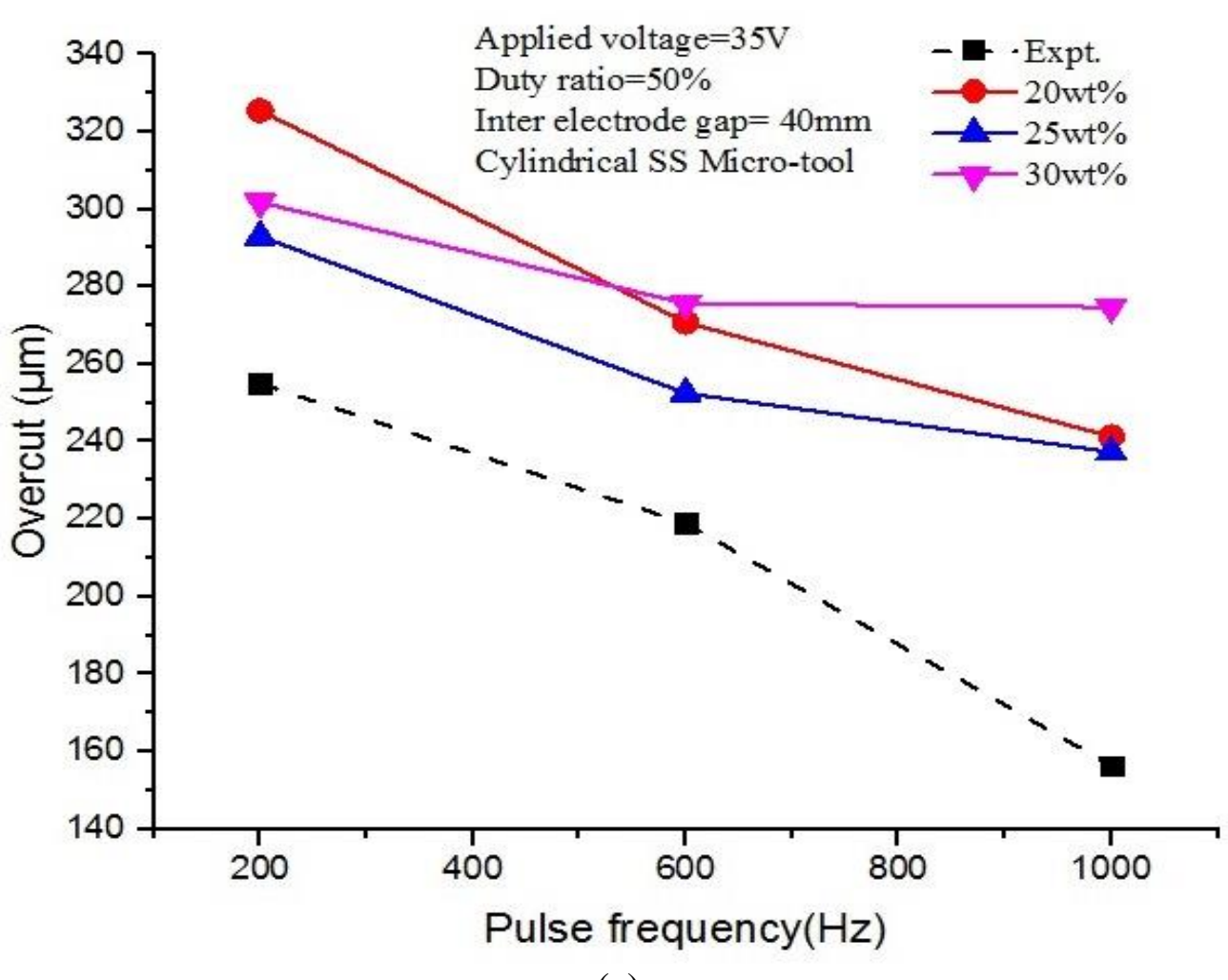

(c)

Figures 3. (a) - (c) Effect of various parameters on OC at different electrolyte concentration (a) applied voltage, (b) duty ratio and (c) pulse frequency.

\section{Parametric Influence on HAZ}

Figures 4 (a) - (c) show the influences of applied voltage, electrolyte concentration, duty ratio and pulse frequency on average heat affected zone (HAZ) area. In ECDM process a large amount of heat is generated during the micro-machining on glass. A little portion of this heat is radiated, some is absorbed to the electrolyte by convection and remainder is conducted to the workpiece. The main cause of the HAZ formation around the machining zone is due to the heat energy conducted to the workpiece. It is observed from Figure 4 that HAZ area almost gradually increases with increase of applied voltage, electrolyte concentration and duty ratio and it becomes higher at $55 \mathrm{v} / 30 \mathrm{wt} \%$. From the Figure 4 (a) it can be highlighted that voltage has a predominant effect on HAZ and higher electrolyte concentration has the highest effectiveness on it. From the Figure 4 (b) it is obviously tendered that at $40 \%$ duty ratio HAZ is comparatively low, keeping other parameters constant. The experimental results reveal that HAZ area can be reduced by decreasing the duty ratio after $50 \%$ and increasing the pulse frequency of the applied voltage up to $600 \mathrm{~Hz}$. From the Figure 4 (c) it is observed that at lower pulse frequency, sparking rate become higher that causes higher heat affected zone and it is found at $600 \mathrm{~Hz}$ lower $\mathrm{HAZ}$ formed and at $200 \mathrm{~Hz}$ higher when varying pulse frequency, keeping other parameter constant. 


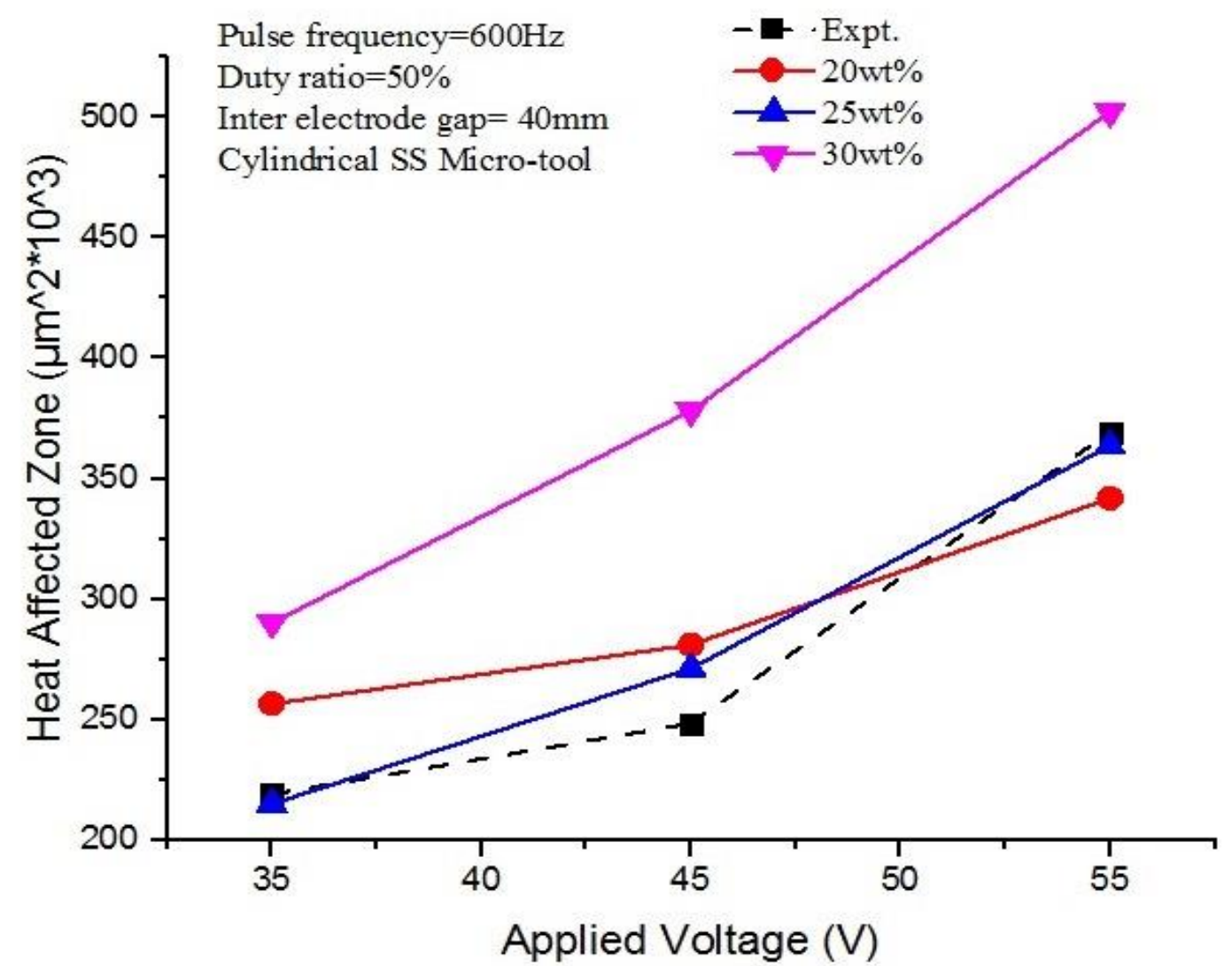

(a)

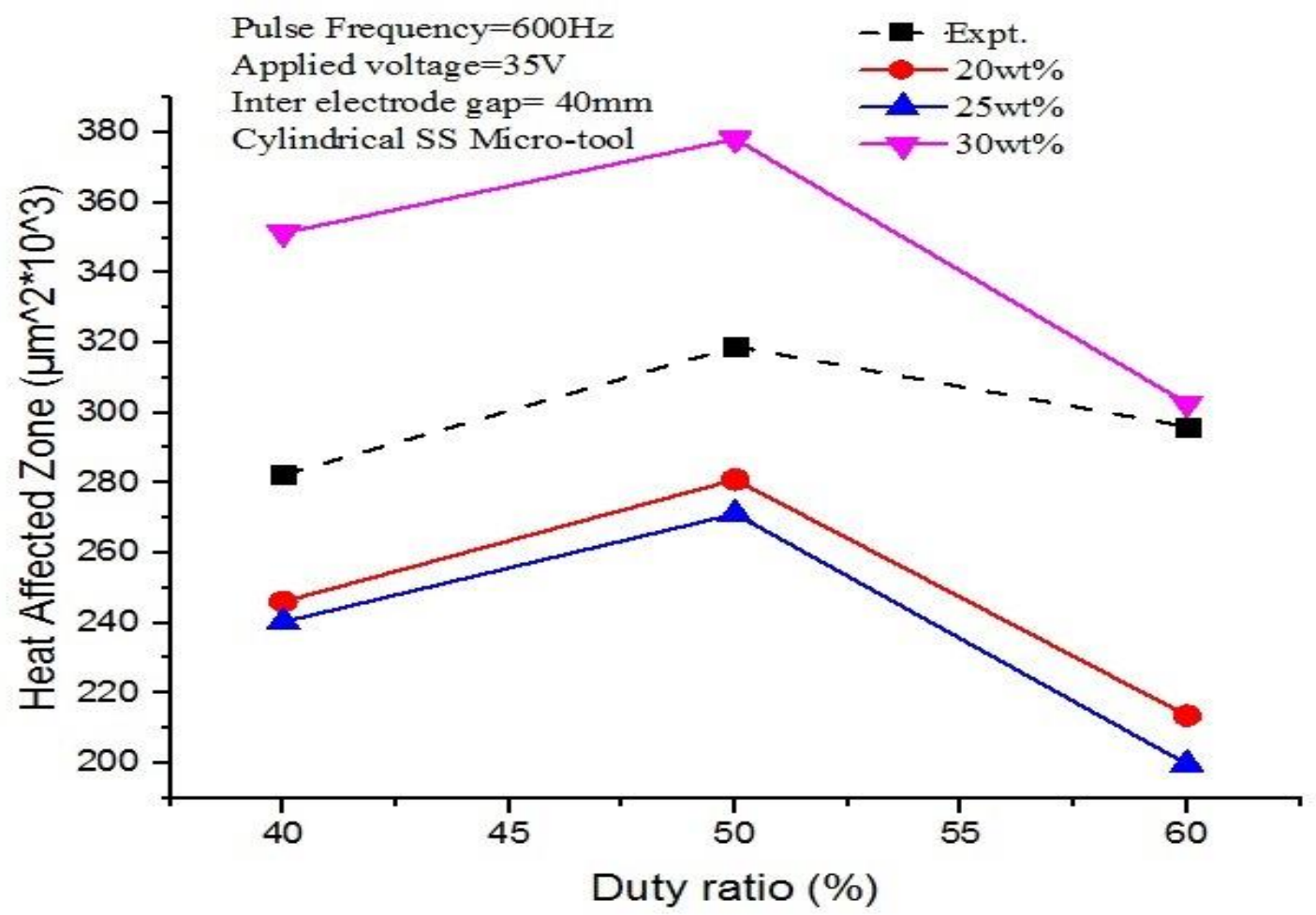

(b) 


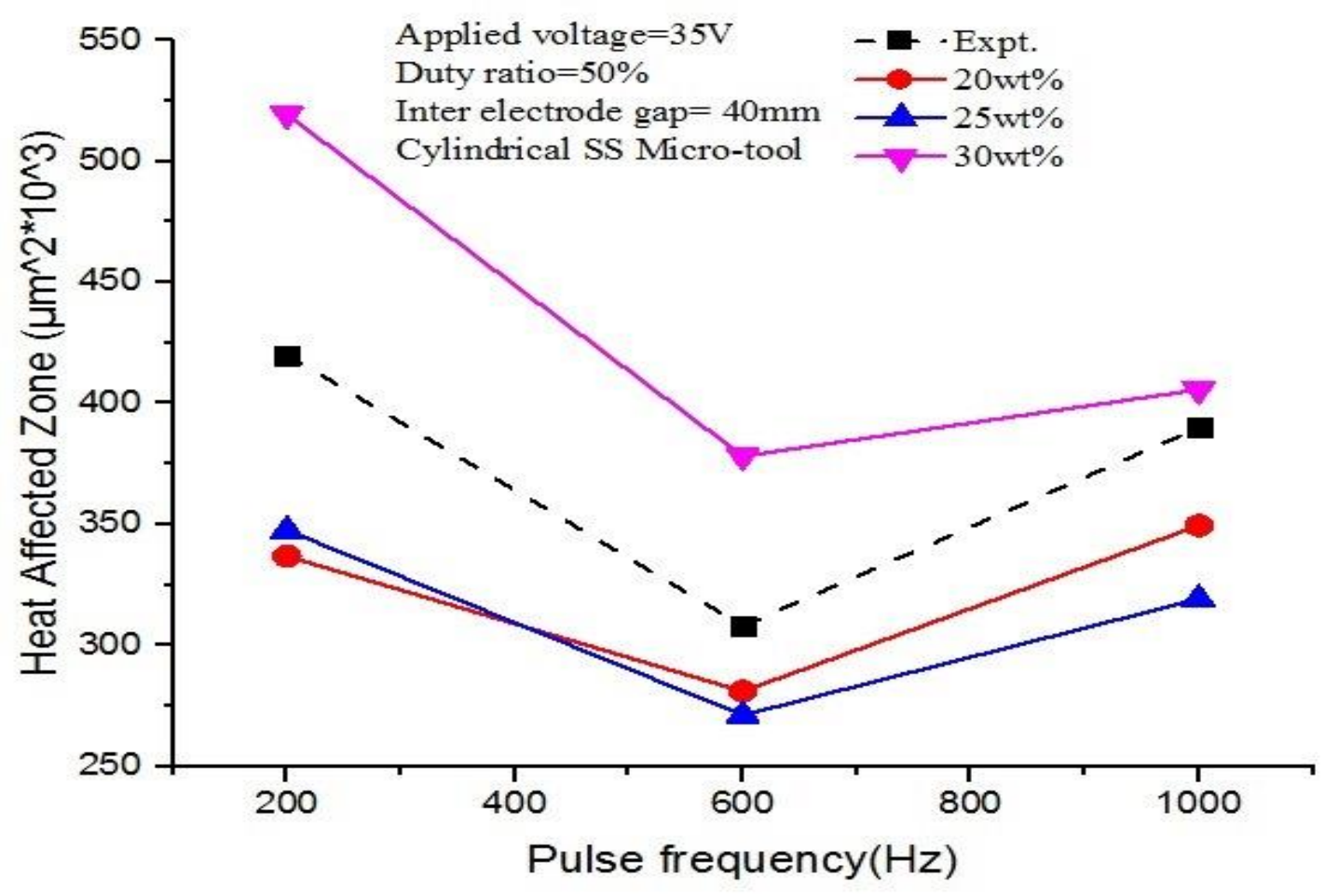

(c)

Figures 4. (a) - (c) Effect of various parameters on HAZ at different electrolyte concentration (a) applied voltage, (b) duty ratio and (c) pulse frequency.

\section{Parametric Influence on Surface Roughness}

The influences of applied voltage, electrolyte concentration, duty ratio and pulse frequency on surface roughness when micro-channel is cut on glass using $\mathrm{NaOH}$ as electrolyte are shown in Figures 5 (a) - (c) respectively. From the Figures 5 (a)-(b) it is clear that surface roughness increases as voltage and duty ratio is increased due to increase in sparking rate but it decreases only at 50 volts, $25 \%$ electrolyte concentration and $55 \%$ duty ratio. The surface texture of micro-channel becomes more irregular at higher voltage due to high thermal shock. Large amount of heat is produced into the machined channel during sparking and as a result, HAZ area increases and makes irregularities on the surface of the work piece that increased surface roughness of the microchannel. If the rate of sparking is continuous and stray sparking is less, side wall sparking reduced then better surface finish may be found. From the Figure 5 (c) it is observed that if pulse frequency is increased, initially surface roughness is decreased because pulse on-time is decreased since the rate of sparking and stray sparking are reduced. But at higher pulse frequency, it is very difficult to control the continuous sparking that causes irregularities on the machining surface. So, after that surface roughness is increased. Evaluation profile of surface roughness as graphical representation is shown in Figure 6 which is found during the measurement of $R_{a}$ of micro-channel machined at $55 \mathrm{v} / 30 \mathrm{wt} \% / 40 \% / 200 \mathrm{~Hz}$ on glass. 


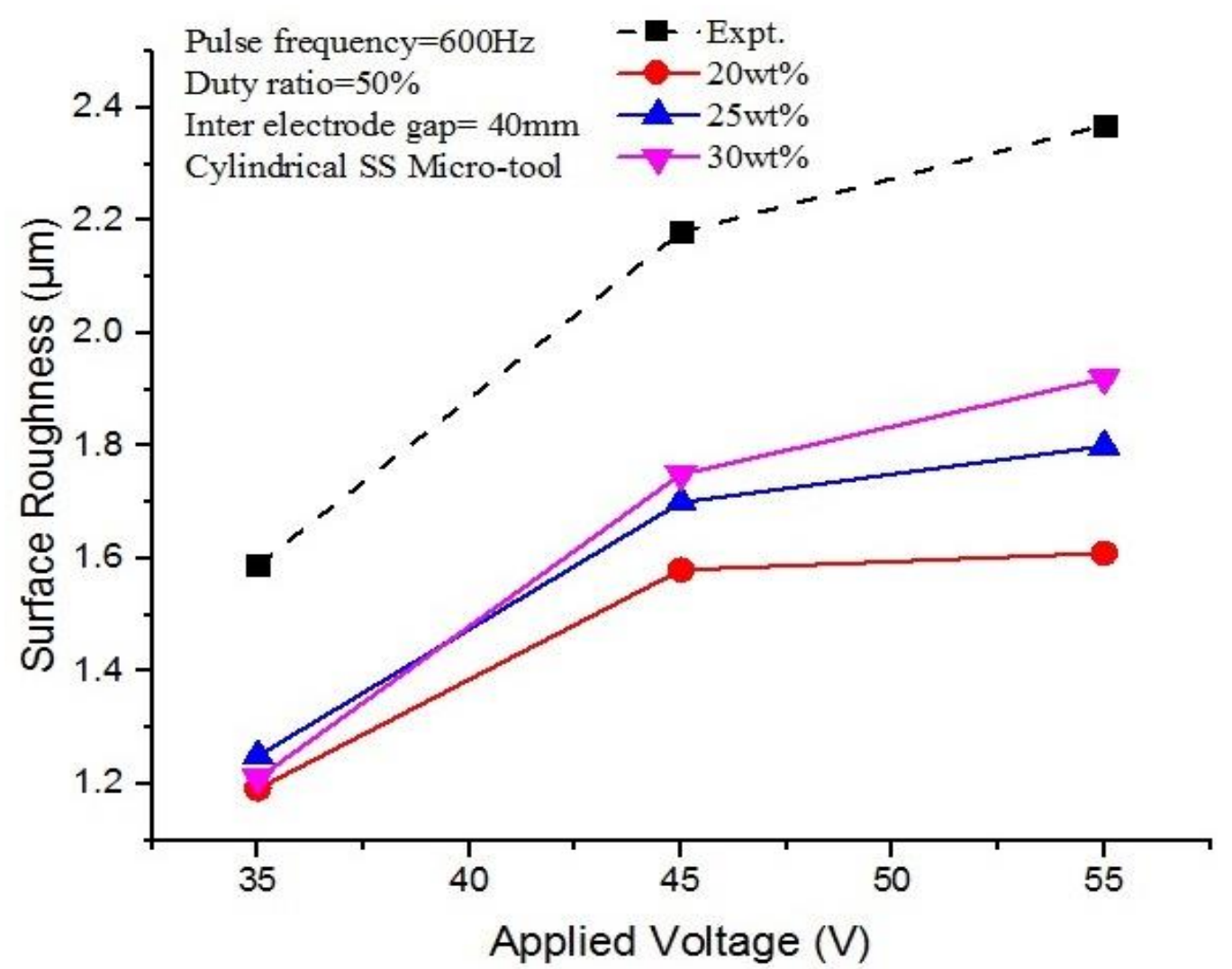

(a)

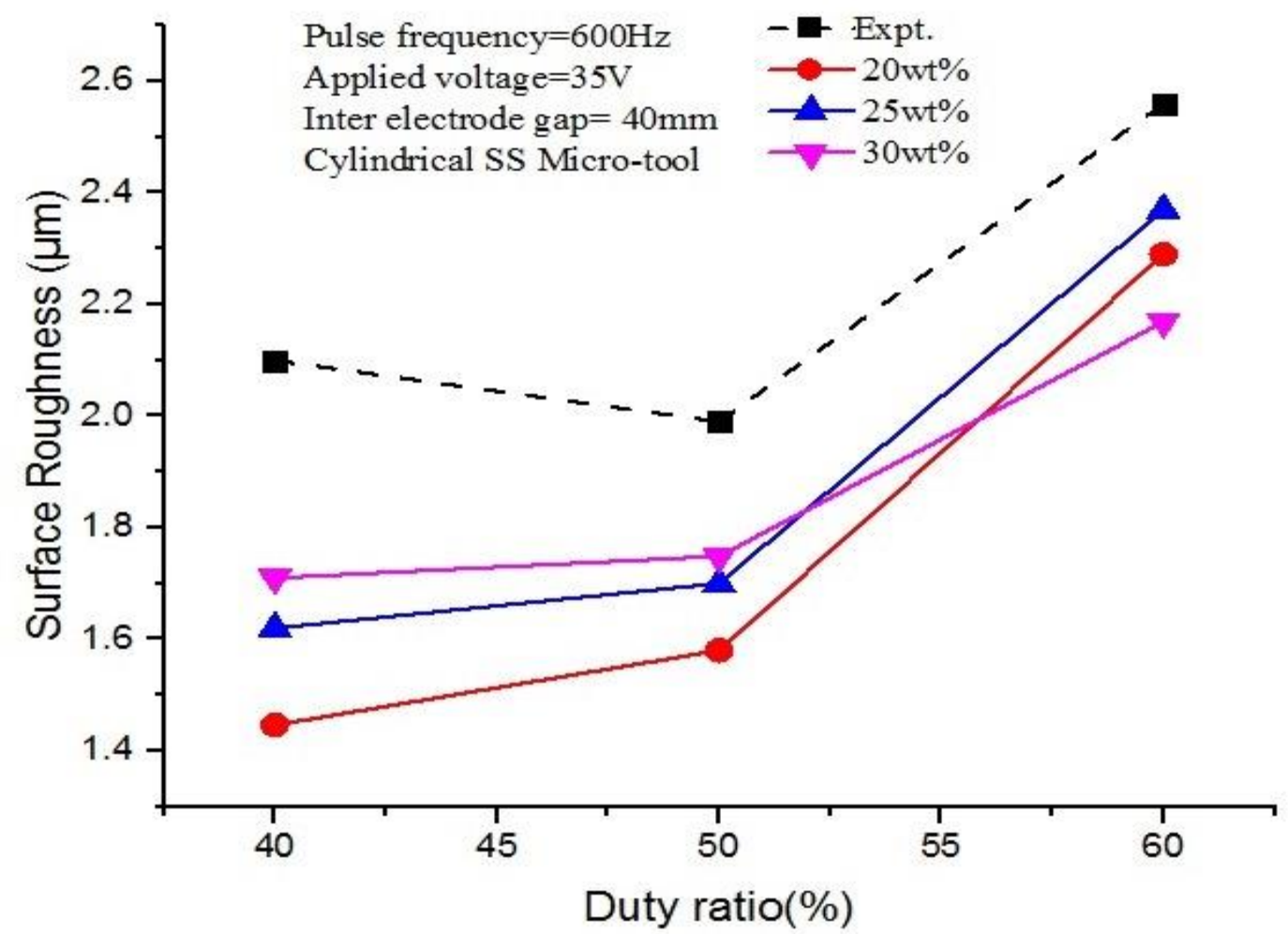

(b) 


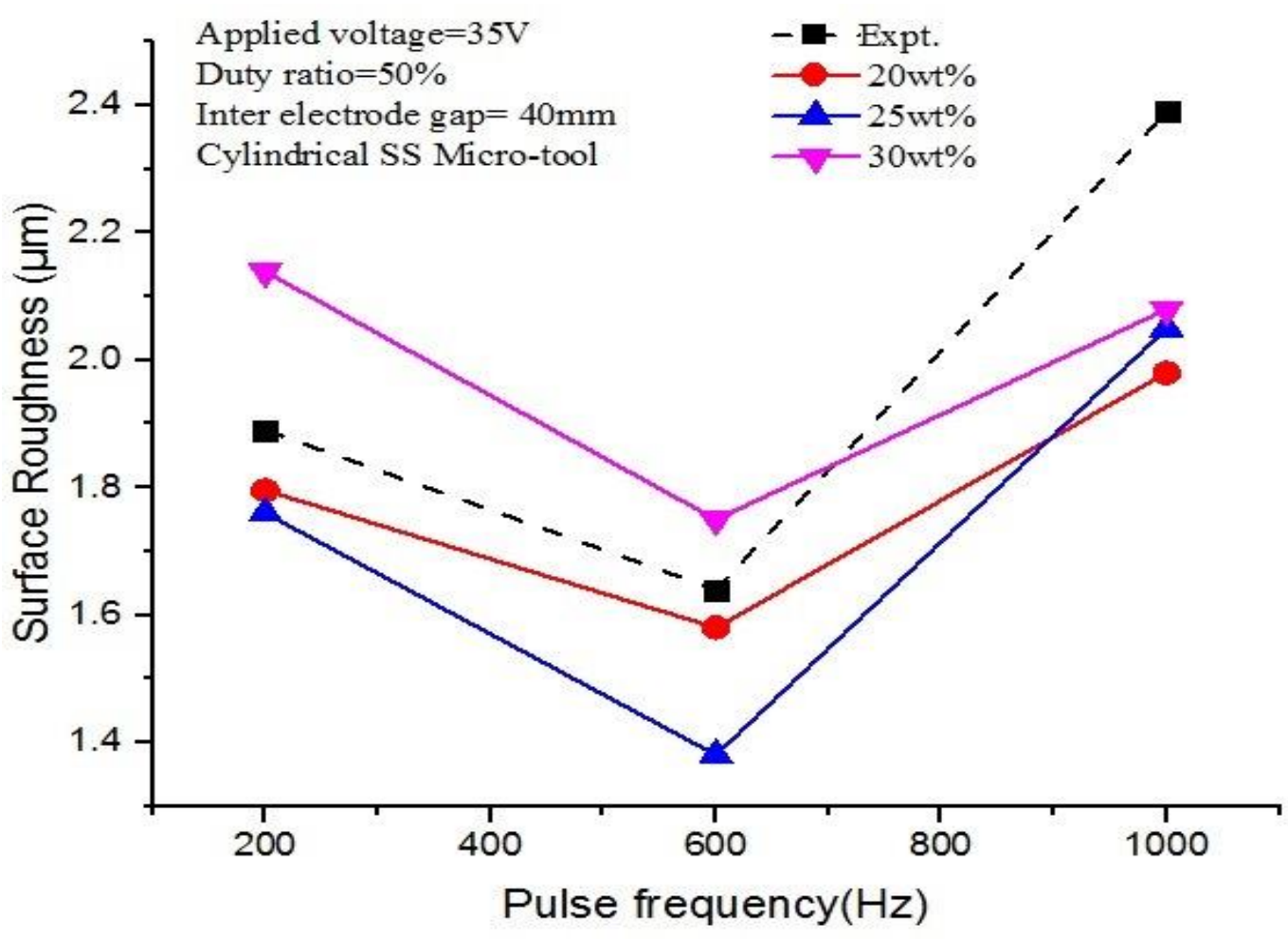

(c)

Figures 5. (a) - (c) Effect of various parameters on Surface Roughness at different electrolyte concentration (a) applied voltage, (b) duty ratio and (c) pulse frequency.

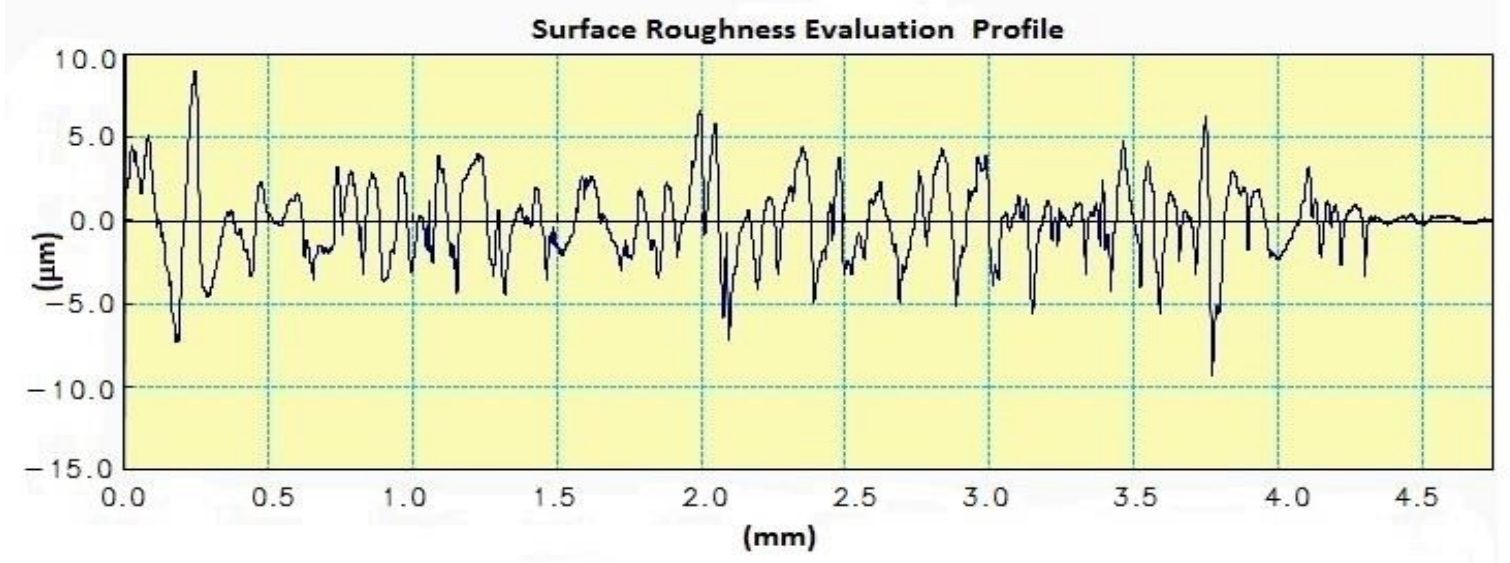

Figure 6. Graphical evaluation of surface roughness at 55V/30wt\%/40\%/200Hz.

\section{Mathematical Modeling and Optimization}

Mathematical model has been developed to correlate the micro-ECDM process parameters and the co-efficient of those parameters during micro-channel cutting on glass. The empirical model on MRR, OC, HAZ and $\mathrm{R}_{\mathrm{a}}$ of micro-ECDM has been established and expressed as Eq. (2)., Eq. (3), Eq. (4) and Eq. (5).

$$
\begin{gathered}
\mathrm{Y}(\mathrm{MRR})=135.1-12.89 \mathrm{X}_{1}+13.79 \mathrm{X}_{2}+1.83 \mathrm{X}_{3}-0.1685 \mathrm{X}_{4}+0.1532 \mathrm{X}_{1}^{2}-0.2119 \mathrm{X}_{2}^{2}- \\
0.0115 \mathrm{X}_{3}^{2}+0.000051 \mathrm{X}_{4}^{2}+0.0149 \mathrm{X}_{1} * \mathrm{X}_{2}-0.01112 \mathrm{X}_{1} * \mathrm{X}_{3}-0.000282 \mathrm{X}_{1} * \mathrm{X}_{4}-0.0226 \mathrm{X}_{2} * \mathrm{X}_{3} \\
+0.000235 \mathrm{X}_{2} * \mathrm{X}_{4}+0.001618 \mathrm{X}_{3} * \mathrm{X}_{4} \\
\mathrm{Y}(\mathrm{OC})=-466+17.92 \mathrm{X}_{1}-54.3 \mathrm{X}_{2}+40.51 \mathrm{X}_{3}-0.5607 \mathrm{X}_{4}-0.3061 \mathrm{X}_{1}^{2}+0.827 \mathrm{X}_{2}^{2}-0.3906 \\
\mathrm{X}_{3}^{2}+0.000079 \mathrm{X}_{4}^{2}+0.3854 \mathrm{X}_{1} * \mathrm{X}_{2}+0.0732 \mathrm{X}_{1} * \mathrm{X}_{3}+0.004739 \mathrm{X}_{1} * \mathrm{X}_{4}-0.1640 \mathrm{X}_{2} * \mathrm{X}_{3} \\
+0.00713 \mathrm{X}_{2} * \mathrm{X}_{4}+0.000098 \mathrm{X}_{3} * \mathrm{X}_{4}
\end{gathered}
$$




$$
\begin{gathered}
\mathrm{Y}(\mathrm{HAZ})=523-15.31 \mathrm{X}_{1}-125.6 \mathrm{X}_{2}+59.93 \mathrm{X}_{3}-0.2134 \mathrm{X}_{4}+0.1815 \mathrm{X}_{1}^{2}+2.338 \mathrm{X}_{2}^{2}- \\
0.5115 \mathrm{X}_{3}^{2}+0.000389 \mathrm{X}_{4}^{2}+0.6355 \mathrm{X}_{1} * \mathrm{X}_{2}-0.1883 \mathrm{X}_{1} * \mathrm{X}_{3}-0.000099 \mathrm{X}_{1} * \mathrm{X}_{4}-0.0806 \mathrm{X}_{2} * \mathrm{X}_{3}- \\
0.01026 \mathrm{X}_{2} * \mathrm{X}_{4}-0.000550 \mathrm{X}_{3} * \mathrm{X}_{4}
\end{gathered}
$$

$$
\begin{array}{r}
Y\left(R_{a}\right)=-11.000+0.2114 X_{1}+0.0958 X_{2}+0.2716 X_{3}-0.001941 X_{4}-0.001796 X_{1}^{2}-0.001515 X_{2}^{2} \\
-0.002089 X_{3}^{2}+0.000002 X_{4}^{2}+0.001421 X_{1} * X_{2}-0.001276 X_{1} * X_{3}+0.000011 X_{1} * X_{4}- \\
0.000811 X_{2} * X_{3}-0.000044 X_{2} * X_{4}+0.000004 X_{3} * X_{4}
\end{array}
$$

Analysis of variance of $\mathrm{P}$ value and F-ratio test were introduced for justification and validation of the goodness of the developed mathematical models. Since the calculated values of F-ratio for the lack of fit are found to be less than the standard F-ratio values (2.32260) for 10 DOF or P value 0.05 for MRR, OC, HAZ and surface roughness, it can be ascertained that the second order regression models are adequate at $95 \%$ confidence level with 10 degrees of freedom (DOF) to represent the relationship between micro-machining performances and the machining parameters of the microECDM process. The values of $\mathrm{R}^{2}$ and adj. $\mathrm{R}^{2}$ for MRR, OC, HAZ, $\mathrm{R}_{\mathrm{a}}$ are $99.21 \%, 97.77 \%, 98.94 \%$, $99.48 \%$ and $98.51 \%, 95.82 \%, 98.01 \%, 99.02 \%$ respectively that represents the validation of that mathematical models.

Many-objective optimization has attractive attention and gradually developed into the field of micro-machining research work. GA is faster; more efficient as compared to the other optimization methods, provides a list of good solutions that's can be used as per requirement but not give a single solution like RSM. Genetic algorithm can be used to solve the engineering optimization problems as a form of complex non-linear problems. In genetic algorithm, five phases are observed which initial population, fitness function, selection, and cross over and finally mutation. 80 chromosomes were generated randomly and they are involved to regenerate crossover and iterated until the stop condition of $n=1000$ generation is reached for MRR, OC, HAZ and $R_{a}$ for single as well as multi objective optimization of those machining criteria and the probability of crossover .80 and probability of mutation is chosen .05 Equation (6) represents the minimized function of the output parameters of MRR, OC, HAZ and $R_{a}$.

So minimize the multi objective function

$$
\begin{gathered}
\mathrm{Y}\left(\mathrm{MRR}, \mathrm{OC}, \mathrm{HAZ}, \mathrm{R}_{\mathrm{a}}\right)=\mathrm{w}_{1} \mathrm{Y}(1 / \mathrm{MRR})+\mathrm{w}_{2} \mathrm{Y}(\mathrm{OC})+\mathrm{w}_{3} \mathrm{Y}(\mathrm{HAZ})+\mathrm{w}_{4} \mathrm{Y}(\mathrm{Ra}) \\
\mathrm{w}_{1}=\mathrm{w}_{2}=\mathrm{w}_{3}=\mathrm{w}_{4}=\text { weightage for output parameter }=1
\end{gathered}
$$

Figure 7 shows the parametric condition and best fitness for MRR, OC, HAZ and $\mathrm{R}_{\mathrm{a}}$ based on GA and it is found that maximized $\mathrm{MRR}$ is $119.963 \mathrm{mg} / \mathrm{hr}$ at the parametric combination $55 \mathrm{~V} / 30 \mathrm{wt} \% \mathrm{NaOH} / 40 \% / 200 \mathrm{~Hz}$. It is found that minimized OC $(81.8577 \mu \mathrm{m})$ in $35 \mathrm{~V} / 26 \mathrm{wt} \% \mathrm{NaOH} / 60 \% / 1000 \mathrm{~Hz}$ and minimized $\mathrm{HAZ}\left(159.632 \quad \mathrm{X} \quad 10^{3}{\mu \mathrm{m}^{2}}^{2}\right.$ at $35 \mathrm{~V} / 24.553 \mathrm{wt} \% \mathrm{NaOH} / 60 \% / 645 \mathrm{~Hz}$ and also the minimized surface roughness $(0.94642 \mu \mathrm{m})$ is achieved at $35 \mathrm{~V} / 20 \mathrm{wt} \% \mathrm{NaOH} / 40 \% / 525 \mathrm{~Hz}$ based on GA. Figure 8 show the graphical view of pareto optimal score histogram of MRR, OC, HAZ and $\mathrm{R}_{\mathrm{a}}$ and machining range with praetor front based on GA. A Pareto front approximation acts as a performance indicator and provides the set of optimal trade-off solutions for multi-response optimization problems. It will be very important to the researcher to take decision and performance assessment by finding out the ideal point if it became continuity, convexity, spread and uniformity. The suitable parametric condition and performance criteria, maximised $M R R=119.846 .70 \mathrm{mg} / \mathrm{hr}$ and minimised $\mathrm{OC}=291.646 \mu \mathrm{m}$, minimized HAZ area $588.26 \times 10^{3} \mu \mathrm{m}^{2}$ and minimized surface roughness $(2.37 \mu \mathrm{m})$ at $55 \mathrm{~V} / 30 \mathrm{wt} \% \mathrm{NaOH} / 40 \% / 200 \mathrm{~Hz}$ that is experimentally validated. Some debris, micro-scatter, thermal effect has been observed analysing the SEM. Figure 9 and 10 show the optical microscopic view and SEM image of micro-channel and micro-slot and micro-blind hole cutting at $55 \mathrm{v} / 30 \mathrm{wt} \% / 40 \% / 200 \mathrm{~Hz}$. 


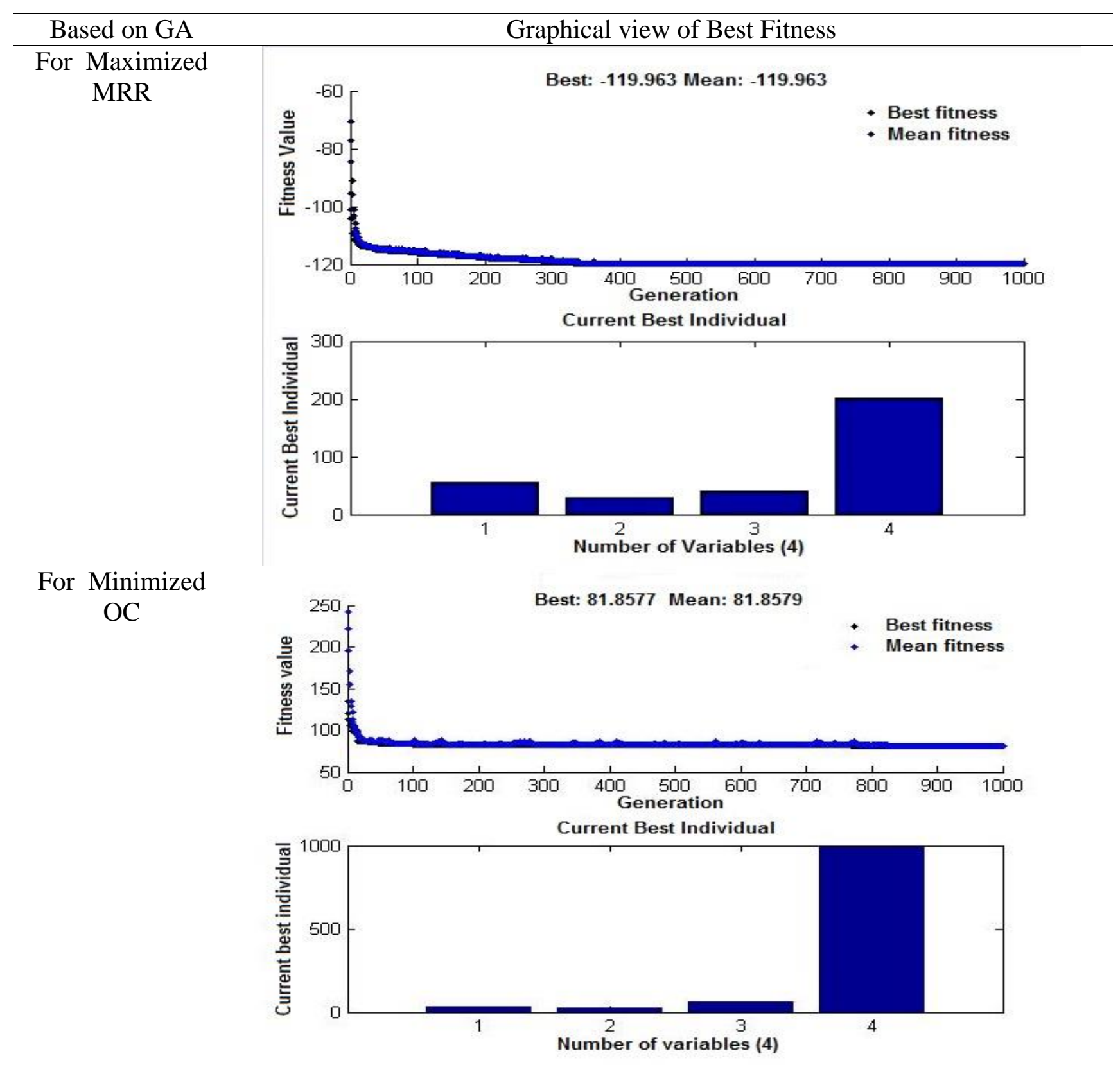


For Minimized

HAZ

For Minimized

Surface

Roughness
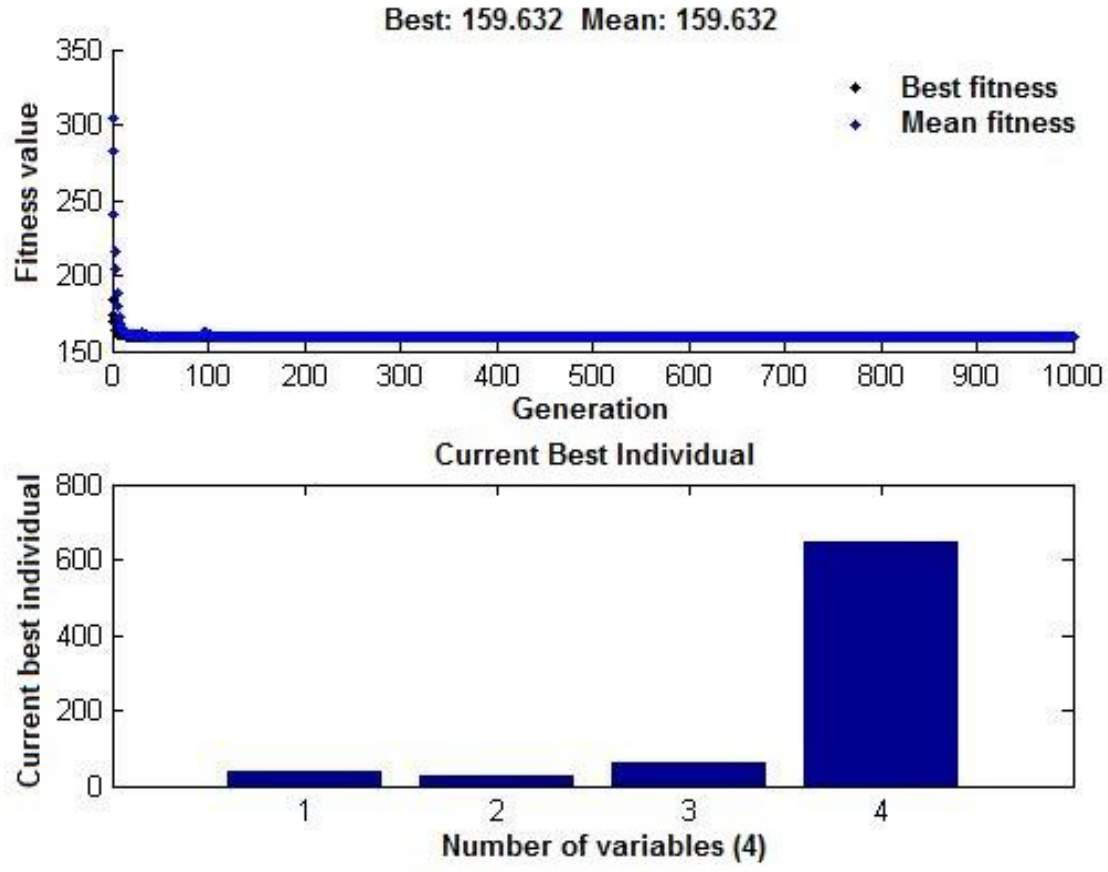

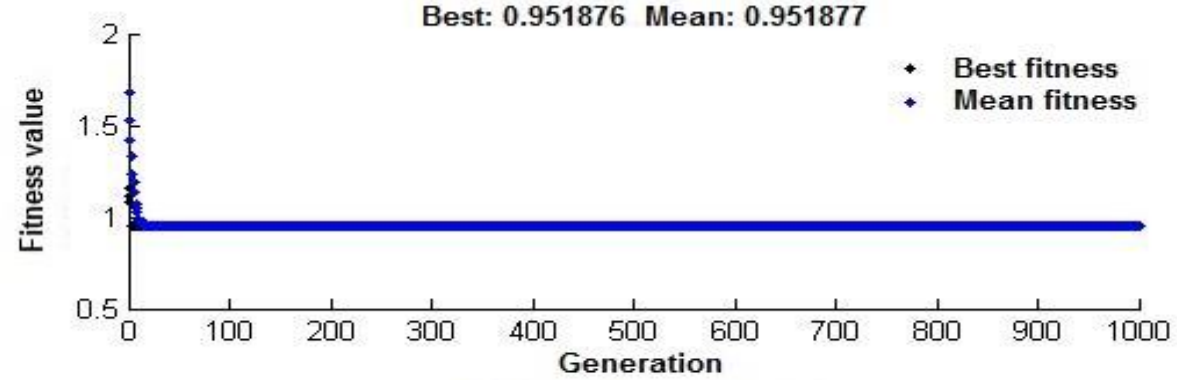

Current Best Individual

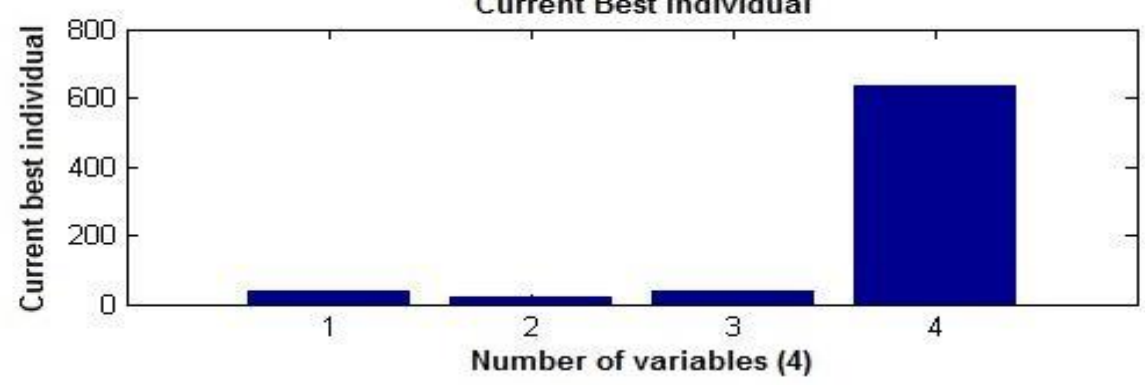

Figure 7. Parametric condition and fitness of MRR, OC, HAZ and surface roughness based on GA. 

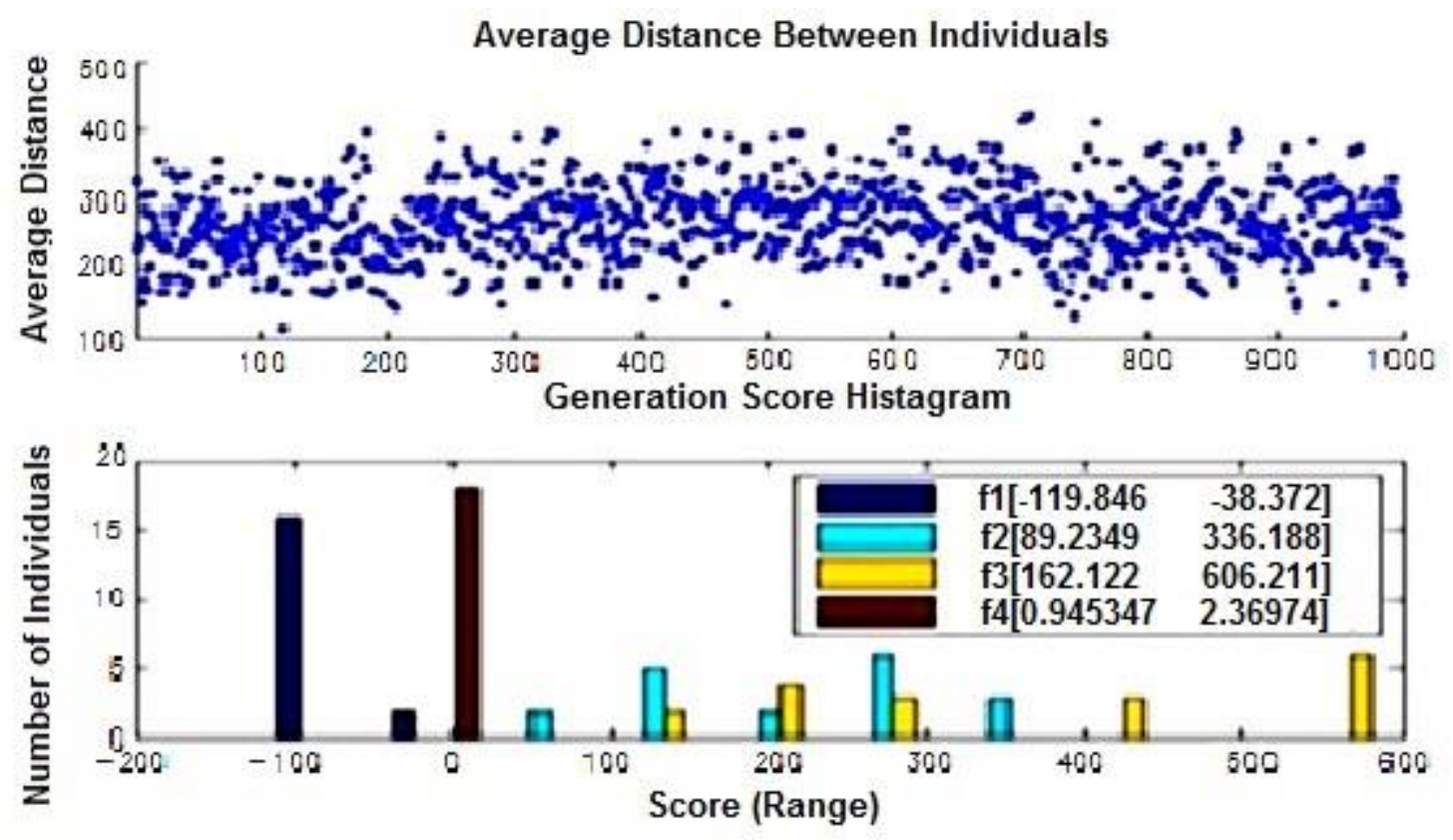

Figure 8. Pareto-front and score histogram of machining criteria based on GA.

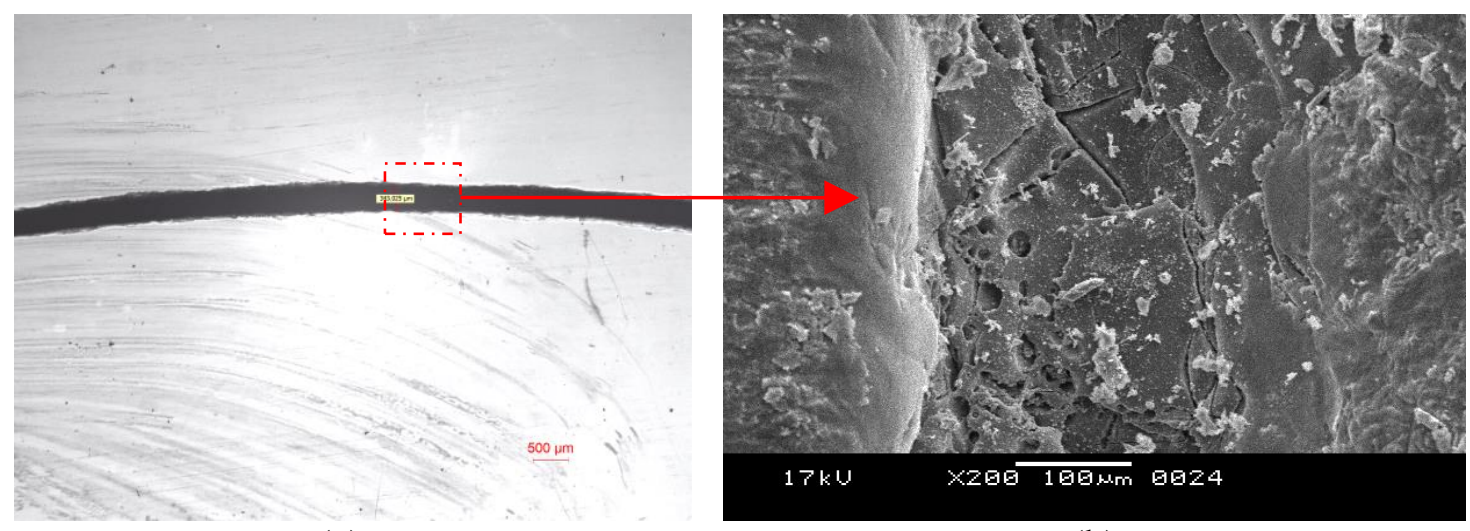

(a)

(b)

Figure 9. Optical (a) and SEM (b) image of micro-channel cutting at 55v/30wt $\% / 40 \% / 200 \mathrm{~Hz} / \mathrm{IEG}$ $40 \mathrm{~mm}$. 


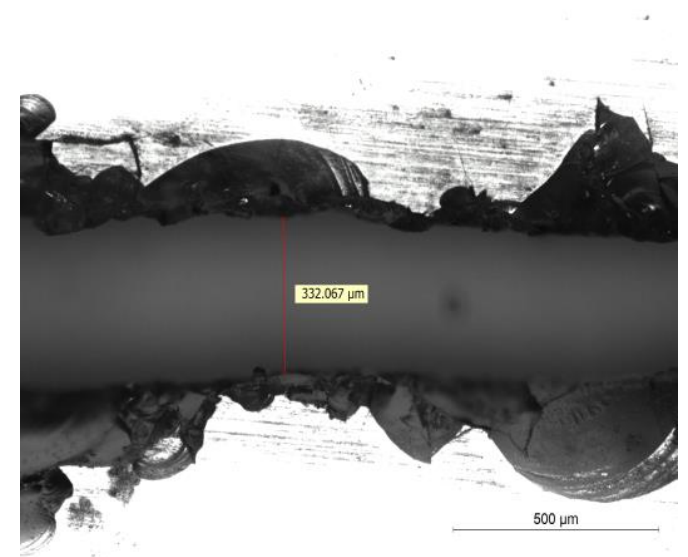

(a)

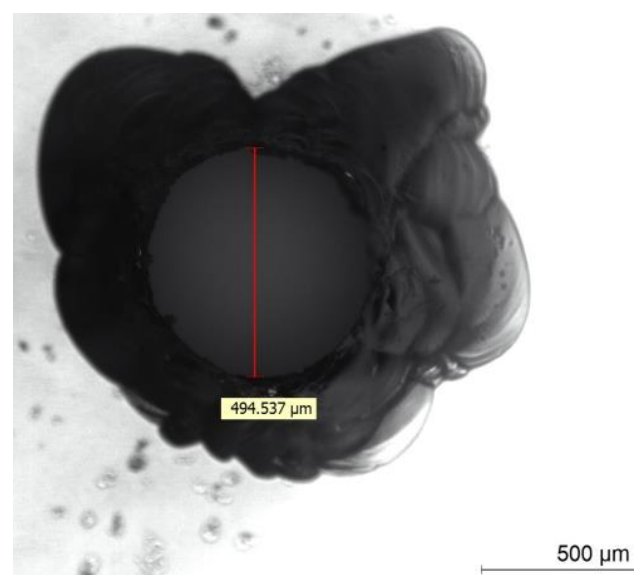

(b)

Figure 10. Microscopic view of (a) micro-slot, (b) micro-hole cutting at 55v/30wt $\% / 40 \% / 200 \mathrm{~Hz}$ with $1.35 \mathrm{~mm}$ machining depth.

\section{CONCLUSIONS}

From the present investigations on the micro-ECDM performances, it can be concluded that microECDM can be utilized to machine electrically non-conducting harder brittle materials like glass and can also be engaged for micro-channel cutting, micro-slot cutting as well as micro-hole applications. Within the limitations of the developed micro-ECDM system, the following conclusions may be drawn out-

- MRR increases when the applied voltage, electrolyte concentration, duty ratio is increased and decrease, if pulse frequency is decreased using $\mathrm{NaOH}$ electrolyte for micro-channel cutting on glass by ECDM process.

- Overcut always increases with increase of applied voltage, electrolyte concentration, duty ratio but it decreases with increase of pulse frequency up to $600 \mathrm{~Hz}$ after that it will increase.

- HAZ area almost gradually increases with increase of applied voltage, electrolyte concentration and duty ratio and it becomes higher at $55 \mathrm{~V}$ and $30 \mathrm{wt} \%$ electrolyte concentration.

- The experimental results reveal that HAZ area can be reduced by decreasing the duty ratio after $50 \%$ and increasing the pulse frequency of the applied voltage up to $600 \mathrm{~Hz}$. But after that increasing of pulse frequency heat affected zone area is increased.

- HAZ area increases and makes irregularities on the surface of the job specimen that increased surface roughness of the micro-channel and if pulse frequency is increased, initially surface roughness is decreased but at higher pulse frequency, it is very difficult to control the continuous sparking that causes irregularities on the machining surface.

- From the above investigations it is concluded that best parametric condition for microchannel as well as micro-slot cutting on glass is 55Volt/30wt $\% \mathrm{NaOH} / 40 \%$ duty ratio/pulse frequency $200 \mathrm{~Hz} /$ Inter electrode gap $40 \mathrm{~mm}$.

- Machining Depth can be increased using down word pressurised automated spring feeding with Cam-follower mechanism and achieved higher machining depth.

\section{ACKNOWLEDGEMENT}

The authors acknowledge the financial support provided by UGC under CAS-IV programmed of Production Engineering Department, Jadavpur University, Kolkata-32, India. 


\section{REFERENCES}

[1] Basak, I.; Ghosh, A. Mechanism of spark generation during electrochemical discharge machining: a theoretical model and experimental verification. Journal of Materials Processing Technology.1996;62:46-53.

[2] Bhattacharyya, B.; Doloi, B.; Sorkhel, S.K. Experimental investigations into electrochemical discharge machining $(\mathrm{ECDM})$ of non-conductive ceramic materials. Journal of Materials Processing Technology.1999;95:145-154.

[3] Jain, V.K.; Dixit, P.M.; Pandey, P.M. On the analysis of the electrochemical spark machining process. International Journal of Machine Tools \& Manufacture.1999;39(1):165-186.

[4] Mediliyegedara, T.K.K.R., De Silva, A.K.M., Harrison, D.K., McGeough, J.A. New developments in the process control of the hybrid electro chemical discharge machining (ECDM) process. Journal of Materials Processing Technology.2005;167:338-343.

[5] Wüthrich, R.; Fascio, V. Machining of non-conducting materials using electrochemical discharge phenomenon-an overview. International Journal of Machine Tools \& Manufacture. 2005; 45(9):1095-1108.

[6] Sarkar, B.R.; Doloi, B.; Bhattacharyya, B. Parametric analysis on electrochemical discharge machining of silicon nitride ceramic. International Journal Advanced Manufacturing Technology. 2006; 28(9), 873-881.

[7] Kim, D.J., Ahn, Y., Lee, S.H. and Kim, Y.K. Voltage pulse frequency and duty ratio effects in an electrochemical discharge micro-drilling process of Pyrex glass. International Journal of Machine Tools \& Manufacture. 2006;46:1064-1067.

[8] Zheng, Z. P.; Su, H. C.; Huang, F. Y.; Yan, B. H. The tool geometrical shape and pulse- off time of pulse voltage effects in a Pyrex glass electrochemical discharge micro drilling process. Journal of Micromechanics \& Microeneering. 2007; 17(2):265-272.

[9] Yan, B. H., Yang, C. T., Huang, F. Y. and Lu, Z. H. Electrophoretic deposition grinding (EPDG) for improving the precision of micro holes drilled via ECDM. Journal of Micromechanics \& Microengineering. 2007; 17:376-383.

[10] Jain, V. K., Adhikary, S. On the mechanism of material removal in electrochemical spark machining of quartz under different polarity conditions Journal of Materials Processing Technology. 2008;200:460-470.

[11] Sarkar B.R.; Doloi B.; Bhattacharyya B. Experimental investigation into electrochemical discharge micro drilling on advanced ceramics. International Journal of Manufacturing Technology and Management.2008;13:(2/3/4),214-225.

[12] Sarkar B.R.; Doloi B.; Bhattacharyya B. Investigation into the influences of the power circuit on the micro-electrochemical discharge machining process, Proceedings of the Institution of Mechanical Engineers, Part B: Journal of Engineering Manufacture. 2009;223 (2): 133 -144.

[13] Han, M. S.; Min, B. K; Lee, S. J. Geometric improvement of electrochemical discharge micro-drilling using an ultrasonic-vibrated electrolyte. Journal of Micromechanics \& Microengineering. 2009; 19: 065004.

[14] Cheng, C. P., Wu, K. L., Mai, C. C., Hsu, Y. S. and Yan, B. H. Magnetic field-assisted electrochemical discharge machining. Journal of Micromechanics \& Microengineering. 2010; 20:075019.

[15] Liu, J. W., Yue, T. M., Guo, Z. N. An analysis of the discharge mechanism in electro chemical discharge machining of particulate reinforced metal matrix composites. International Journal of Machine Tools \& Manufacture.2010;50:86-96.

[16] Yang, C.-K., Cheng, C.-P., Mai, C.-C., Wang, A. C., Hung, J.-C., Yan, B.-H. Effect of surface roughness of tool electrode materials in ECDM performance. International Journal of Machine Tools \& Manufacture.2010;50:088-1096. 
[17] Cheng C. P., Wu, K. L, Mai, C. C., Yang, C. K., Hsu, Y. S., Yan, B. H. Study of gas film quality in electro-chemical discharge machining. International Journal of Machine Tools \& Manufacture. 2010; 50:689-697.

[18] Sankar, A. R., Bindu, V.S.S, Das, S. Coupled effects of gold electroplating and electrochemical discharge machining processes on the performance improvement of a capacitive accelerometer. Micro systemTechnology.2011;17:1661-1670.

[19] Wei, C., Hu, D., Xu, K., Ni, J. Electro-chemical discharge dressing of metal bond microgrinding tools. International Journal of Machine Tools \& Manufacture. 2011;51:165-168.

[20] Cao, X. D., Kim, B. Y. and Chu, C. N. Hybrid Micromachining of Glass using ECDM and Micro Grinding. International Journal of Precision Engineering and Manufacturing. 2013;14 (1): 5-10.

[21] Baoyang, J.; Shuhuai, L.; Kevin, W.; Jun, N. Modeling and experimental investigation of gas film in micro-electrochemical discharge machining process International Journal of Machine Tools and Manufacture.2015; 90: 8-15.

[22] Hajian, M.; Razfar, M.R.; Movahed, S. An experimental study on the effect of magnetic field orientations and electrolyte concentrations on ECDM milling performance of glass. Precision Engg. 2016; 45:322-33.

[23] Saranya, S.; Nair, A.; Ravi Sankar, A. Experimental investigations on the electrical and 2Dmachining characteristics of an electrochemical discharge machining (ECDM) process. Microsystem Technologies. 2016;22: 1-9.

[24] B. Mallick; B.R. Sarkar; B. Doloi; B. Bhattacharyya. Analysis on Electrochemical Discharge Machining during Micro-channel Cutting on Glass International Journal of Precision Technology. 2017;7(1):32-50.

[25] S. Elhami \& M. R. Razfar. Effect of ultrasonic vibration on the single discharge of electrochemical discharge machining. Journal of Materials and Manufacturing Processes. 2017; $1-8$

[26] P. K. Singh, A. K.Das, G. Hatui,G. C. Nayak. Shape controlled green synthesis of CuO nanoparticles through ultrasonic assisted electrochemical discharge process and its application for super capacitor. Materials Chemistry and Physics. 2017;198:16-34

[27] S. Elhami, M.R. Razfar. Analytical and experimental study on the integration of ultrasonically vibrated tool into the micro electro-chemical discharge drilling. Precision Engineering. 2017;47:424-433.

[28] M. Hajian \& M. R. Razfar \& A. H Etefagh. Experimental study of tool bending force and feed rate in ECDM milling. Int. J. Adv. Manuf. Technology. 2017;91:1677-1687.

[29] W.Tang, X.Kang and W. Zhao. Enhancement of electrochemical discharge machining accuracy and surface integrity using side-insulated tool electrode with diamond coating. Journal of Micromechanics and Microengineering. 2017;27:6.

[30] M. Han, K. W. Chae and B.K. Min. Fabrication of high-aspect-ratio microgrooves using an electrochemical discharge micro milling process. Journal of Micromechanics and Microengineering. 2017; 27: 5.

[31] J.M.Pujara , K.D.Kothari and A.V.Gohil. An investigation of material removal rate and kerf on WEDM through grey relational analysis. Journal of Mechanical Engineering and Sciences. 2018;12(2):3633-3644.

[32] S.M. Chan, K.H. Chong and Basil T. Wong. The effect of $10 \mu \mathrm{m}$ micro channel on thermohydraulic performance for single phase flow in semi-circular cross-section serpentine. Journal of Mechanical Engineering and Sciences.2018; 12(2):3724-3737. 